\title{
Analysis and Strategy of Public Signs Translation
}

\author{
Lei Liang \\ School of Foreign Studies, Xi'an University 710065, China \\ 810489066@qq.com
}

Keywords: public signs; Chinese-English translation; Translation strategies

\begin{abstract}
With the deepening of China's internationalization process, more and more international friends come to China for tourism, business, visit and study. Large and medium-sized cities have English signs in public places, and bilingual signs can be seen everywhere. We can say that the city public sign is the name card of a city and the symbol of a city civilization. The quality of bilingual sign reflects the internationalization level of a city. This paper aims to analyze the current situation of public signs through examples, and briefly analyze the causes of mistranslation, so as to put forward some beneficial countermeasures and suggestions to solve and eliminate such problems and create a good language environment.
\end{abstract}

\section{The introduction}

With the increasingly close contact between China and the world, more and more international friends come to our country to work, travel and live. As an important window for the world to understand China, public sign is a unique application style appearing in public areas and an important part of social language. Urban public sign is a name card of a city, a symbol of urban civilization, which can give people an intuitive impression and convey hints, warnings, reminders and requests. The quality of the Chinese-English bilingual logo reflects the internationalization level of a city, which not only shows the openness of the city to the outside world, but also promotes the further communication between China and other countries. Public logo has a long history in abroad, they are already quite mature and has a certain standard, but in our country, the public logo of English-Chinese translation starts late, lacking of standards and system, and in recent decades, along with the further increase of internationalization, especially the 2008 Beijing Olympic Games, the 2010 Shanghai world expo in 2011 and xi an held in the park and public logo was also more widespread attention. However, at present, the wrong and irregular public signs in English have seriously affected China's external image and brought unnecessary trouble and inconvenience to international friends.

\section{Common mistakes in the translation of public signs}

After careful analysis of English translations of public signs in many cities, we can see some similarities. After classification and discussion, these mistakes can be roughly divided into the following categories:

\subsection{A simple list of pinyin}

We can see street names everywhere like this: NANGUANZHENG ST; SHUYUAN MEN; DONGDAJIE; NAN XINJIE; SHANGDE LU; SHANGJIAN LU; MEITU SHENGHUO, of course it's easy for people who are familiar with the city to see where it's going, but for people from other cities and countries, how can this simple list of pinyin make sense?

\subsection{Misuse of words and grammatical errors}

These errors directly reflect the translator's unprofessionalism, lack of in-depth research and literal translation word by word, ignoring the inherent connections. Such as: "export" is a word that means to sell and send goods to another country. While "exit" means "a way out of a public building or 
vehicle". For example, "restroom" is not a restroom but a public restroom, and restroom should be labeled "lounge" or "lobby'. Misuse of words like this can be misleading and can be detrimental to the effective delivery of information. In addition, grammatical errors are reflected in the incorrect application of word parts of speech and sentence structure. For example, verbs are used as nouns, adjectives as nouns, etc. There are also singular and plural errors and article errors.

\subsection{The difference of thinking}

Nida once pointed out that "For a truly successful translation, it is even more important to be familiar with two cultures than to master two languages, because words have meaning only in the cultural context in which they work." Different cultural background and way of thinking is also the important cause of translation errors, for example, there is a warning about property in many sites, a lot of public signs are translated according to the thinking of Chinese "Please take care of your property", it is not in conformity with the English expression habits, it should be "Keep an eye on your personal belongings"; "Please economize on electricity" should be changed into "Please Save Energy" according to the English language usage habit. "Closed" is better than "Stop paying fees" for the international friends to understand. In English, people are familiar with "NO DUMPING", but not "No Littering", another example, "Never Leave Your Valuables Unattended" is more acceptable, but not "Take Good Care of Your Belongings". and "AUTOMATIC DOOR, CAUTION" is better than "Be Careful of Automatic Door", because the former one is accord with the requirements of accuracy and brevity. The expression of Chinese public signs is direct and straightforward. It is customary to use imperative sentences, such as "Don't smoke". "No smoking" is widely accepted in China, but now the international is more inclined to use "Thank you for not smoking". We hope more and more people like this saying.

\subsection{Term inconsistency}

The same public expression should be maintained wherever it appears, or it will affect the city's image. We can see the different parts of various marks on the different trash cans "Recycled-Non-recycled; Recyclable-Not-recyclable; Recyclable-Non-recyclable." Also "Li River" and "Lijing River", "Fubo Hill", "Whirl-pool Hill" and "Subduing Hill".

\section{Policies to standardize public signs}

After a lot of research by experts, the translation of public signs has been clearly classified and standardized. What we should do is to call on all sides to take various effective measures to solve the existing problems, mainly from the following aspects:

\subsection{Reinforce the management}

The problems existing in the translation of public signs are not only the problems of translation, but also the reflection of internationalization degree. As a result, the management departments should raise the awareness of the importance of public signs 'translation, strengthening the supervision of it. The relevant functional departments of the government should strengthen the management and standardization of the translation of public signs. In fact, many mistakes are caused in the production process, such as the omission or repetition of letters and the inversion of the alphabetical order, which requires our production staff to be familiar with English and be careful and responsible. At the same time, strengthen the training and management of related personnel. The administration department shall also hold regular training courses on foreign-related tourism translation, providing English translation training for tourism management personnel, tourism translation practitioners, and managers and self-employed operators of foreign-related tourism and culture enterprises.

\subsection{Pay attention to cross-cultural awareness}

Translation is a cross-cultural means of communication. It is the act of transforming one linguistic information into another on the basis of accuracy and smoothness. This characteristic of translation 
determines that the translator must be proficient in the characteristics, language style and idiomatic style of both Chinese and English. In order to make the translation of public signs conform to international standards and let international friends get information clearly, it is necessary to require our translation to conform to the habit of English, which requires translators to pay attention to the cultivation of cross-cultural thinking and avoid the influence of Chinese thinking.

\subsection{Imitate the foreign countries}

In fact, the most effective and direct way to translate public signs is to imitate or learn from foreign public signs, so as to facilitate foreigners' understanding. On the bus, for example, we will set some special seats for the sick and pregnant, in North America, The seats are marked on "The courtesy seats", we can directly use the expression method, and parking is full with "occupied", if the literal meaning to translate into "The parking is full", is too far-fetched, does not conform to the habit of English, instead, cannot be understood by the foreigners.

\section{Conclusion}

The internationalization of China's influence in the world, while the development of the world has affected the China. Public signs plays an important role in a city, ambiguity in any translation and misuse, will result in hordes of tourists. Only if it is concise and clear with standardization, public signs can really play the role of conveying information, becoming the window of the world to China. On the premise of ensuring the acceptance of target language readers, Chinese cultural characteristics should be spread as far as possible to attract overseas tourists and arouse the desire of target language readers. However, the improvement of the translation quality of public signs cannot only be left to the language and culture level. The correct translation of public signs requires the joint efforts of the government, society, translation professionals and university research centers.

\section{Acknowledgment}

This research was financially supported by the Social Science Fund Project of Xi'an "Research on the International Publicity Translation of Xi 'an Public Signs from the Perspective of Ecological Translation" (Grant NO. 2019ZDZT15) and the Teaching Reform Project in Xi'an University (Grant NO. JY2019KGA12).

\section{References}

[1] Newmark, Peter. Approaches to Translation [M]. Shanghai: Shanghai Foreign Language Education Press, 2001.

[2] Han Jing, Liu Lijuan. English translation errors and standardization Suggestions for public signs in baoding city.[J]. Hebei: Youth Literator, 2010

[3] Lv Hefa, Shan Liping. A Chinese-English Dictionary on Signs. [M]. Beijing: The Commercial Press

[4] Wang Qing. Functional features and English translation of public signs.[J]. Anhui: Journal of Anhui university of technology (social science edition).2009(5)

[5] Yang Fengli, On the English translation of public signs, .[J]. Jiangsu:Journal of changchun institute of education, 2009(9) 